\title{
EXISTENCE OF GOLDEN PROPORTION IN MAXILLARY ANTERIOR TEETH OF UNIVERSITY OF MALAYA DENTAL STUDENTS
}

E. Sulaiman, M.S. Yaakub, N.A. Zulkifli, M. Abdullah, M.A.G. Gonzalez. Existence of golden proportion in maxillary anterior teeth of University of Malaya dental students. Annal Dent Univ Malaya 2010; 17: 9-14.

\begin{abstract}
Purpose of the study: The objective of this study was to investigate the existence of the golden proportion between the width of the maxillary anterior teeth of undergraduate dental students at University of Malaya.
\end{abstract}

Materials and method: Standardised photographs of 100 dental students' smiles displaying only the lips and the teeth were captured. The images were transferred to a personal computer and the width of the maxillary anterior teeth was measured using an Image Analyzer (Leiqa QWin). Calculations were made according to the Theory of Golden Proportion. The data were statistically analysed using paired student T-test $(\alpha \leq 0.05)$

Results: There was a statistically significant difference between the width of the right lateral incisors and $62 \%$ of the width of the right central incisors (only 19\% subjects had their right lateral incisors in golden proportion with the width of their right central incisors, $\mathrm{M}=12.5 \%, \mathrm{~F}=20.3 \%, \mathrm{p}=0.00)$. A significant difference also existed between the width of the right canines and $62 \%$ of the width of the right lateral incisors (only $17 \%$ of the subjects had the width of their canines in golden proportion with the width of their right lateral incisors, $\mathrm{M}=23.1 \%, \mathrm{~F}=12.2 \%, \mathrm{p}=0.00$ ).

Conclusions: A significant difference existed between the right lateral incisors and $62 \%$ of the right central incisors, and between the right canines and $62 \%$ of the right lateral incisors in both male and female subjects. Mean maxillary anterior tooth proportion among the dental students were 0.70 for laterals to central incisors and 0.82 for canines to lateral incisors. The golden proportion is not a suitable method to relate the maxillary anterior tooth proportions in these Malaysian subjects.

Key words: golden proportion, maxillary anterior teeth, Malaysian subjects

\section{INTRODUCTION}

Maxillary anterior teeth bear a significant effect in aesthetic dentistry as their facial aspects are widely visible during smiling. One of the most important and critical tasks in aesthetic dentistry is creating a
Original Article

E. Sulaiman 1 , M.S. Yaakub ${ }^{2}$, N.A. Zulkifli'
M. Abdullah', M.A.G. Gonzalez

'Senior Lecturer
${ }^{2}$ Dental Student
Department of Conservative Dentistry
Faculty of Dentistry, University of Malaya
50603 Kuala Lumpur, Malaysia
Tel: 03-7967 4806
Fax:03-7967 4533
E-mail: eshamar@um.edu.my
Corresponding author: Dr. Eshamsul Sulaiman

harmonious proportion when restoring or replacing these teeth (1). In treating patients with missing or badly damaged anterior teeth, dentists must determine the tooth shape and proportion in order to achieve optimal results (2). The golden proportion is one of the geometric proportions that has been suggested as a guide to create pleasing anterior restorations. The golden proportion is a constant ratio between the larger and a smaller length. The ratio is approximately $1.618: 1$. In terms of proportion, the smaller tooth is about $62 \%$ the size of the larger one. For example when the ratio between a central incisor and a lateral incisor is in golden proportion, the central incisor is 0.618 larger or $62 \%$ more than the size of the lateral incisor. This constant ratio has been used to determine the proportion of maxillary anterior teeth to achieve an aesthetic restorative result.

In 1973, Lombardi (3) described the proportion of the widths of lateral incisors to central incisors and the width of the canines to lateral incisors following a repeated ratio. They suggested the application of the golden proportion in dentistry. Levin (4) suggested the use of a golden proportion to relate the successive width of maxillary anterior teeth as viewed from the facial aspect. He stated the width of the central incisor should be in golden proportion to the width of the lateral incisor and similarly, the width of lateral incisor should be in golden proportion to the width of the canine. Levin's golden proportion has been proposed in many articles and textbooks as an aesthetic guideline for restoring and replacing maxillary anterior teeth.

It has been reported that only a small proportion of individuals considered to have aesthetic smiles had the golden proportion. Preston (5) evaluated the relationship of the golden proportion to the width of maxillary teeth in American subjects using orthodontic casts and found that the golden proportion 
between the width of maxillary and lateral incisors only existed in $17 \%$ of the casts. Gillen (6) also demonstrated that the golden proportion between the width of maxillary anterior teeth did not correlate with any of the ratios investigated (length: width, width:width and length:length). Ward (7) showed that when the golden proportion was used, the lateral incisor appeared too narrow and the resulting canine was not dominant enough. He suggested that $70 \%$ proportion to be more appropriate.

Mahshid et al. (1) demonstrated that the golden proportion did not exist between the widths of maxillary anterior teeth in the Iranian subjects. A recent study by Ali Fayyad et al. (8) concluded that the golden proportion was not a suitable method to relate the successive width of maxillary anterior teeth in their Arab subjects as they found only $31 \%$ men and $27 \%$ women exhibited the golden proportion. Another study evaluated the influence of varying the dimensions of maxillary lateral incisors on perceived aesthetic smiles, Bukhary et al. (9) found 67\% proportion was the most preferred proportion between lateral incisors and central incisors, followed by a $72 \%$ proportion and concluded that the golden proportion $(62 \%)$ should not be used as the ideal aesthetic standard when creating space for replacement of missing lateral incisors.

The prevalence of the golden proportion between the widths of maxillary anterior teeth varies among different populations and ethnic groups. Thus far, no study has evaluated this relationship in Malaysian subjects. Therefore, the purpose of this study was to investigate the prevalence of the golden proportion in a group of Malaysian subjects.

\section{MATERIALS AND METHOD}

One hundred undergraduate dental students, 26 men and 74 women, with age ranging from 19 to 24 years old participated in the study. The selection criteria required the subjects to have all their natural anterior teeth, no history of orthodontic treatment or tooth size alteration and be of Malaysian population. Those with maxillary anterior restorations, trauma or previous orthodontic treatment or any maxillofacial surgery were excluded from the study.

A standardized frontal image of each subject's face was taken using a digital camera (Nikon D200 Digital SLR, Nikon Inc., USA). The subject's head was positioned with the mid-sagittal plane of the head aligned with the centre of the camera lens and the Frankfort horizontal plane paralleled to the floor. This was done by positioning the subject's head on a dental pantomogram (DPT) machine (Planmeca, Finland) with the light from the machine positioned onto the midline of the face and the interpupillary line (Figure 1). The camera was positioned and adjusted so as to obtain a sharp image of the face from the tip of nose to the tip of chin. The subject was asked to smile and the image was captured during the smile (Figure 2). The images were then transferred to a personal computer. The width of the right maxillary anterior teeth was measured and calculations were made according to the golden proportion theory. All measurements were performed utilizing an image analyzer (Leica QWin, Leica Microsystems GmbH, Wetzlar, Germany). This program was used to measure the apparent mesiodistal width of right maxillary anterior teeth. All measurements were performed by one investigator.

The golden proportion for each subject was measured in the following manner: $62 \%$ of the width of the central incisor was compared to the width of the adjacent lateral incisor. Similarly, $62 \%$ of the width of the lateral incisor was compared to the adjacent canine. The data were statistically analysed using Student's paired t-test at $\leq 0.05$ using SPSS ver. 12.0. Student's paired t-test was also performed on data for males $(n=26)$ and females $(n=74)$.

\section{RESULTS}

The data collected from 100 subjects revealed that $19 \%$ have the width of their right central incisors in golden proportion to the width of their right lateral incisors. $12.5 \%$ of males and $20.3 \%$ of females have the width of their right central incisors in golden proportion to the width of their right lateral incisors.

Seventeen percent of the subjects had the width of their right lateral incisors in golden proportion to the width of their right canines. $23.1 \%$ of males and $12.2 \%$ of females have the width of their right lateral incisors in golden proportion to the width of their right canines.

The mean value for right lateral incisors, canines, $62 \%$ of central incisors and $62 \%$ of lateral incisors are listed in Table 1 . The mean width of the right lateral incisors was $5.90 \mathrm{~mm}( \pm 0.64)$ and $62 \%$ of the right central incisors was $5.24 \mathrm{~mm}( \pm 0.35)$. Mean width of right canines was $4.70 \mathrm{~mm}( \pm 0.66)$ and $62 \%$ of right lateral incisors was $3.64 \mathrm{~mm}( \pm 0.40)$. Differences in individual measurements between the teeth examined are shown in a graph in Figure 1 and Figure 2.

Student's paired t-test showed that there was a statistically significance difference between right lateral incisors $(p=0.00)$ and $62 \%$ of central incisors as well as between the right canines and $62 \%$ of the right lateral incisors $(p=0.00)$. This was true for both males $(p=0.00)$ and females $(p=0.00)$ as well.

\section{DISCUSSION}

One of the most important tasks in aesthetic dentistry is creating harmonious proportions between the widths of maxillary anterior teeth when restoring or replacing these teeth. A mathematical or geometrical relationship between teeth is thought to provide a template to achieve an aesthetic restorative result. It would be 
Table 1. Mesiodistal diameter of right anterior teeth and computed proportion for the central and lateral incisors

\begin{tabular}{lcccc}
\hline \multicolumn{1}{c}{$\mathrm{N}=100$} & $\begin{array}{c}\text { Min } \\
(\mathrm{mm} .)\end{array}$ & $\begin{array}{c}\text { Max } \\
(\mathrm{mm} .)\end{array}$ & $\begin{array}{c}\text { Mean } \\
(\mathrm{mm} .)\end{array}$ & $\begin{array}{c}\text { Std Deviation } \\
(\mathrm{mm} .)\end{array}$ \\
\hline Right central incisors & 7.1 & 10.1 & 8.456 & 0.5011 \\
Right lateral incisors & 3.2 & 7.4 & 5.877 & 0.6456 \\
Right canine & 3.1 & 7.1 & 4.716 & 0.6643 \\
62\% of M-D width of right central incisors & 4.4 & 6.26 & 5.2427 & 0.3479 \\
62\% of M-D width of right lateral incisors & 1.98 & 4.59 & 3.6437 & 0.4002 \\
\hline
\end{tabular}

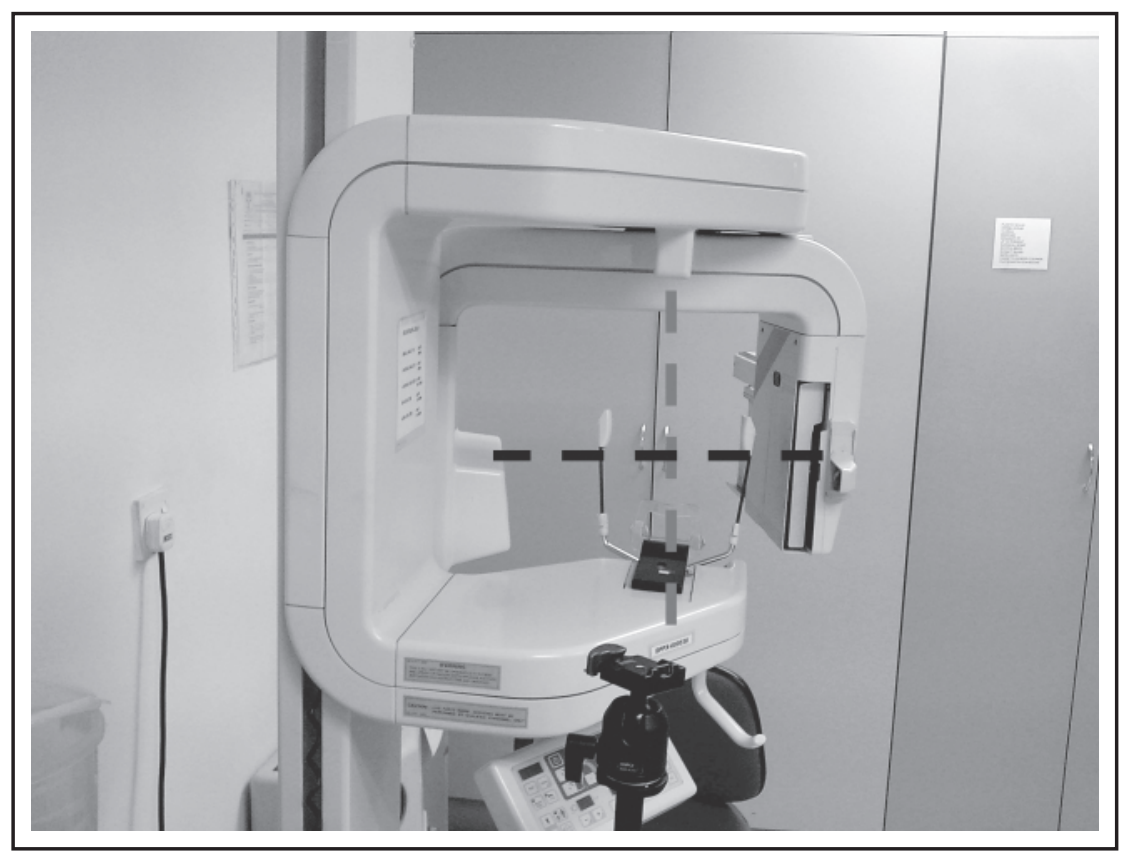

Figure 1. The DPT used to position the subject's head.

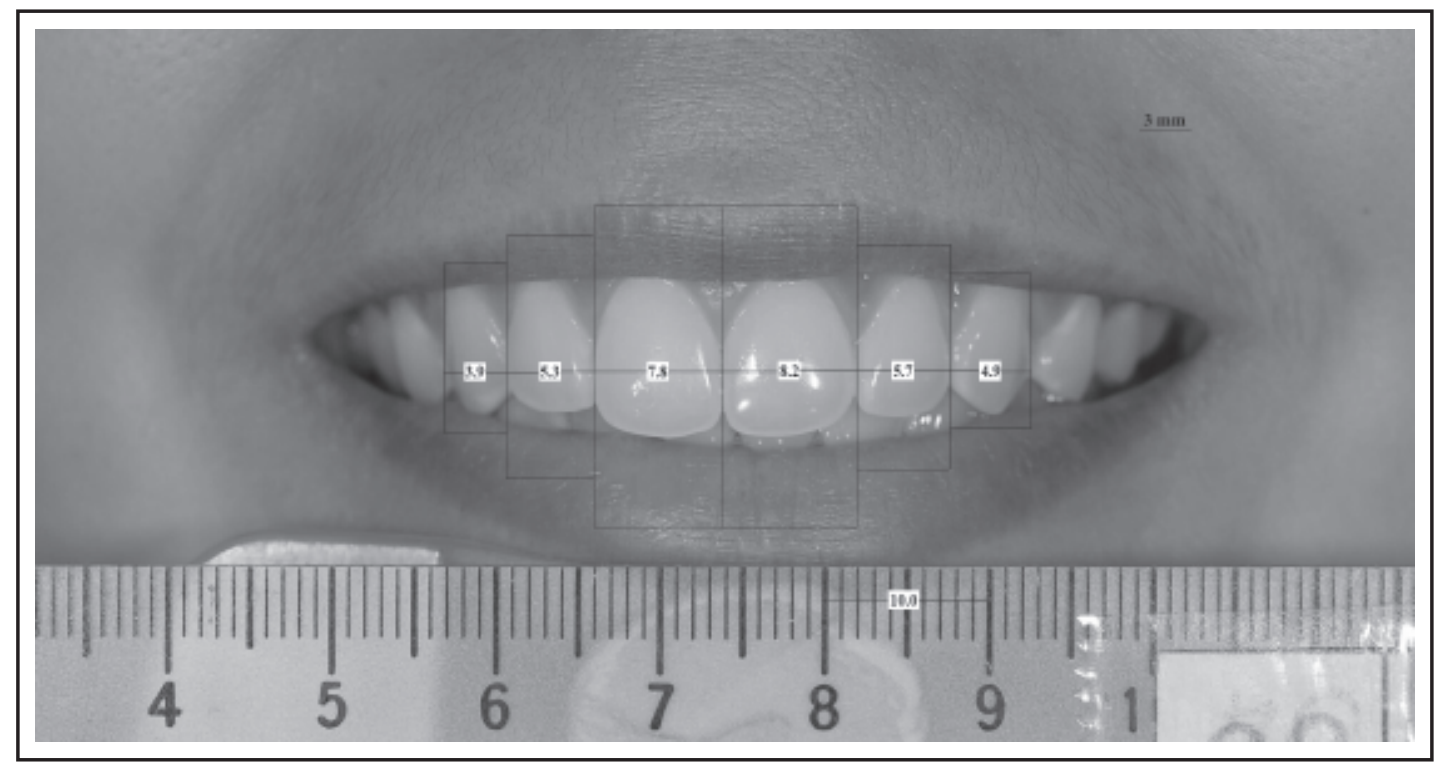

Figure 2. Close-up view of the smile and the method of measurement. 


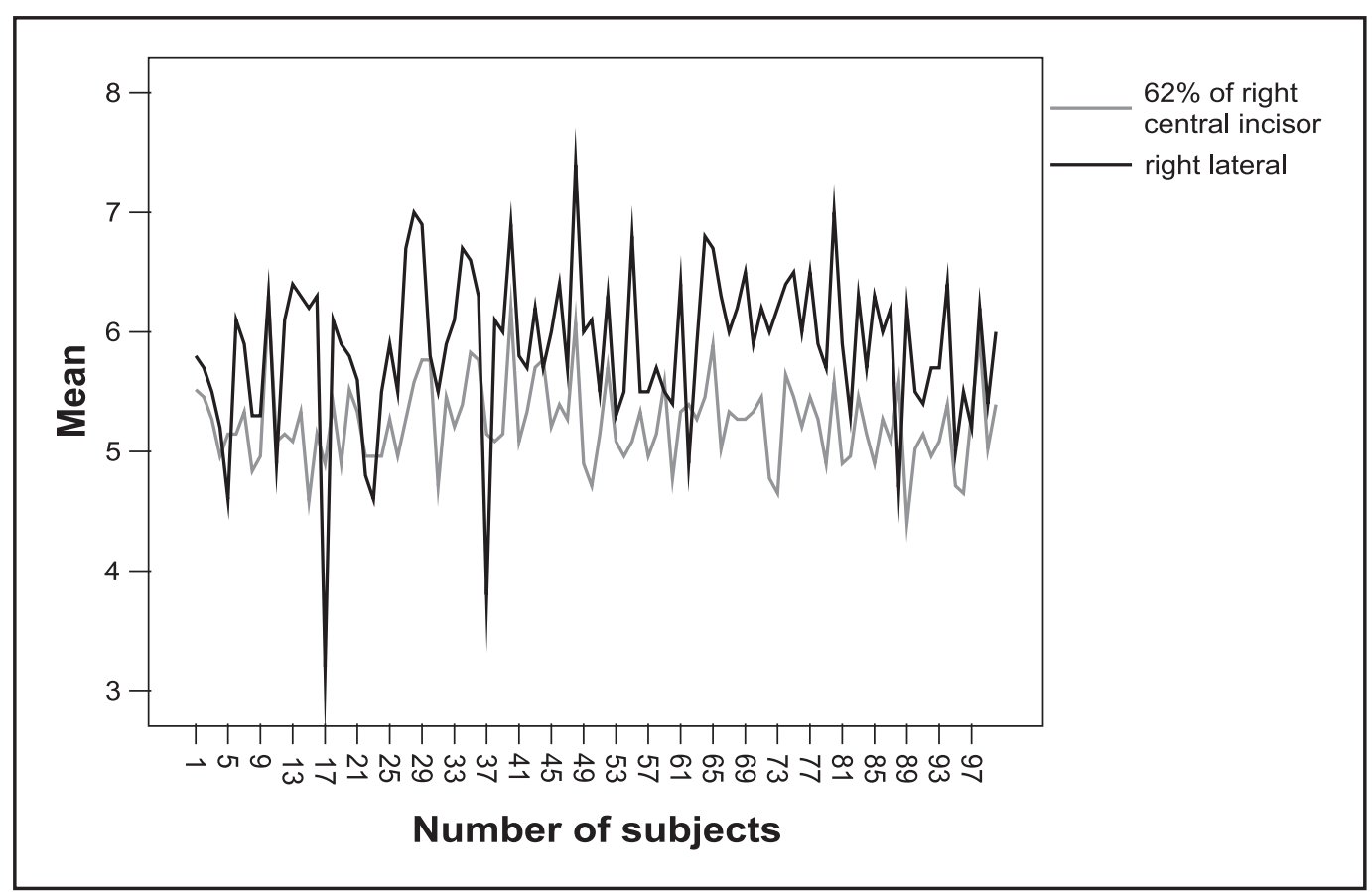

Figure 3. Golden proportion relationship of $62 \%$ of right central incisor (blue line) to the right lateral incisor (red line) in general. (Overlapping of red and blue lines represent the teeth in golden proportion)

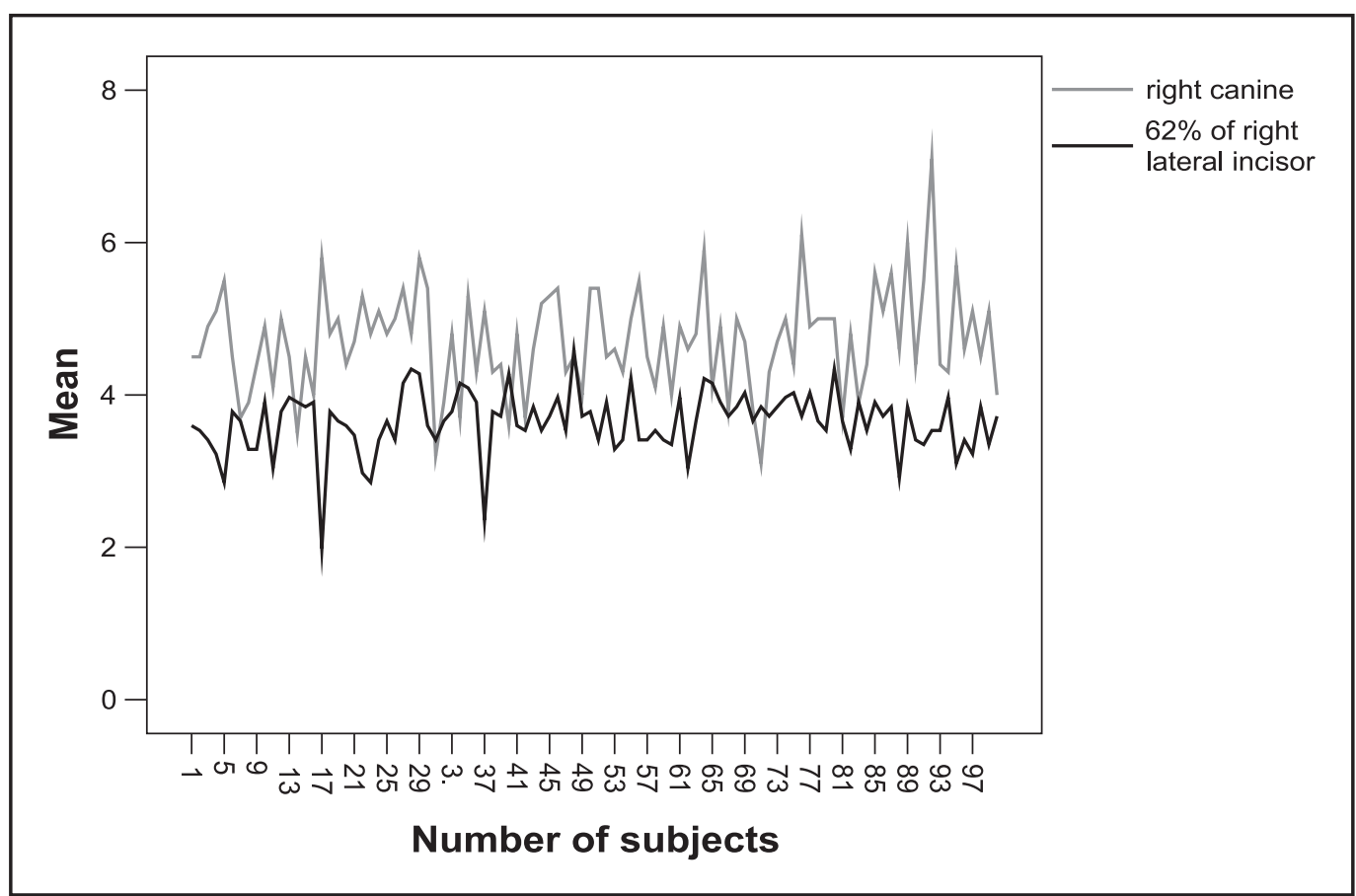

Figure 4. Golden proportion relationship of $62 \%$ of right lateral incisor (red line) to the right canines (blue line) in general. (Overlapping of red and blue lines represent the teeth in golden proportion)

helpful if statistically reliable relationships existed to support existing relationship theories. The golden proportion is a main guideline introduced to facilitate this process. Maxillary anterior tooth proportion has been proposed to be related to a golden proportion. Levin (1978) was the first to assert the existence of the golden proportion. This proportion was employed to determine the relationship between maxillary anterior teeth width.

The selection criteria for the subjects was used to ensure accuracy of measurement. The symmetry, dominance and proportion of maxillary anterior teeth are affected by many factors. Snow (10) stated that in considering only the effect of apparent width on 
symmetry, dominance and proportion, the relative width percentage of teeth is determined by individual tooth alignment within an arch form. He also stated that several factors, including rotation, spacing, overlapping and other forms of malalignment of teeth, all negatively affect the relative proportion of each anterior tooth seen from the frontal view. If the malalignment factors of rotation, diastemas, overlapping, buccoversion and linguoversion are absent or eliminated, the apparent width percentages of the teeth is determined by the curvature of arch itself.

There have been several researchers who had studied the association between maxillary anterior tooth proportion and the golden proportion. The results of their studies have been equivocal with the golden proportion being found in varying proportions of individuals considered to have an aesthetic smile $(1,9,11,12,13)$. The constant $(62 \%)$ used in the golden proportion was adjusted by Bukahry et al. (9) in a study on patient preference in dimensions of replacements for missing maxillary lateral incisors. They found that the most preferred ratio was $67 \%$ followed by $72 \%$. They concluded that the golden proportion should not be considered the ideal aesthetic standard when replacing missing lateral incisors. De Castro et al. (14), in a study with 260 university students, found that only $7.1 \%$ of those with "agreeable" smiles had golden proportion. Other methods using the principle of proportionality have been used which include the recurring esthetic dental (RED) proportion and the golden percentage $(15,16)$. RED proportion is used with the proportion of successive teeth from central incisor to the canine being constant. Ward (16) reported that a majority of North American dentists surveyed in 2007 preferred the smiles created by RED than the golden proportion. The golden percentage is applied to the mesiodistal measurement from canine to canine with each central incisor, lateral incisor and canine occupying 25\%, 15\% and $10 \%$ of that measurement, respectively.

Ali Fayyad et al. (8) evaluated the geometric and mathematical proportions and their relationship to the maxillary anterior teeth. They found that the golden proportion was found to be accurate between the width of the right central and lateral incisors in $31.3 \%$ of men and $27 \%$ of women. These findings are higher as compared to our results where only $12.2 \%$ of males and $20.3 \%$ of females had the width of their right central incisors in golden proportion to the width of their right lateral incisors. Gillen et al. (6) found no correlation exist between tooth dimension and golden proportion. Although in their study the values of tooth width were not measured from frontal view as the theory implies. Besides that, their measurements were made directly on casts. Therefore, those findings could not be compared in our study. The difference in results may be attributed to several factors, the least of which are difference in research methodology as well as differences in the ethnicities of the subjects. The present study utilized data from Malaysian's population with different ethnics groups: Malay, Chinese, Indians and others.

The effect of gender has not been a significant factor in using the golden proportion $(8,13)$. Hasanreisoglu et al. (12) found that there were gender differences between males and females with regards to central incisor and canine dimensions. In the present study, the results for males and females were statistically similar. Anterior teeth dimension for many Asian ethnic groups have yet to be reported. Murthy and Ramani (15) suggested that the ethnicity of the subject should be considered when using the golden percentage.

The differences in the results obtained from other studies may be due to differences in methodology. In some studies, frontal images were taken and transferred to a computer for measurements and calculations (15). In others studies, direct measurements on the patient's cast was used (13) or a combination of both methods (12). In a web-based study, a computer imaging program was used to generate tooth images with different tooth heights and then manipulated the tooth widths to conform to various proportions. Dentists were then asked to rank the images over the internet (2).

There are some factors that need to be considered in determining the golden proportion of maxillary anterior tooth proportions in future studies. First, the image of anterior teeth should be taken from the frontal view and the position of face should be in the midline because a small shift of facial midline will cause error on the symmetry of the teeth of both sides. The dimensions of the image are different at the centre as compared to the side of the image. This is caused by the curvature of the arch and may cause slight error on the measurement of tooth width. This can be corrected by using a special software that corrects this deviation.

Age can also cause bias in the results of the study or research. Different studies were focused on different target groups with a wide age range. Apart from that, variation in sample size may also have contributed to the differences in results.

Although golden proportion has been proposed in the literature as a useful application for achieving proportion and aesthetics, this proportion has not been evident in all aesthetically pleasing smiles. Such aesthetic smiles have been described in different populations $(1,2,15,17,18)$. Wolfart et al. (18) concluded that a most attractive range can be identified for the width-to-length ratios and tooth-totooth proportions of maxillary incisors. Basting et al. (19) have stated that a smile analysis should be performed in relation to facial features to achieve a most aesthetic smile. 


\section{CONCLUSIONS}

Within the limitations of this study, the following conclusions can be derived:

1) $12.5 \%$ of males and $20.3 \%$ of females have the width of their right central incisors in golden proportion to the width of their right lateral incisors while $23.1 \%$ of males and $12.2 \%$ of females have the width of their right lateral incisors in golden proportion to the width of their right canines

2) Gender has no statistically significant effect when golden proportion was applied.

3) Maxillary anterior tooth proportion in Malaysian subjects are 0.70 for lateral to central incisors and 0.82 for canines to lateral incisors.

4) The use of the golden proportion is not a suitable method to relate the maxillary anterior teeth proportion in Malaysian subjects in this study.

\section{REFERENCES}

1. Mahshid M, Khoshvagti A, Varshosaz M, Vallaei N. Evaluation of golden "proportion" in individual with esthetic smile. J Esthet Restor Dent 2004;16: 185-92.

2. Rosentiel SF, Ward DH, Rashid RG. Dentist's preference of anterior tooth proportion-a webbased study. J Prosthodont 2000;9:123-36.

3. Lombardi RE. The principles of visual perception and their clinical application to denture esthetics. J Prosthet Dent 1973;29:358-82.

4. Levin EI. Dental esthetics and the golden proportion. Prosthet Dent 1978;40:244-52.

5. Preston JD. The golden proportion revisited. J Esthet Dent 1993;5:247-51.

6. Gillen RJ, Schwartz RS, Hilton TJ, Evans DB, An analysis of selected normative tooth proportion. Int J Prosthodont 1994;7:410-7.

7. Ward DH. Proportional smile analysis design using recurring eshtetic dental (RED) proportion. Dent Clin North Am 2001;45:143-54.

8. Ali Fayyad M, Jamani KD, Agrawi J. Geometric and mathematical proportion and their relations to maxillary anterior teeth. J Contemp Dent Prac. 2006;1:762-70.
9. Bukhary SM, Gill DS, Tredwin CJ, Moles DR. The influence of varying maxillary lateral incisor dimensions on perceived smile aesthetics. Br Dent J 2007;203:687-93.

10. Snow SR. Esthetic smile analysis of anterior tooth width: The golden percentage. J Esthet Dent 1999;11:177-84.

11. Nikgoo A, Alavi K, Alavi K, Mirfazaelian A. Assessment of the golden ratio in pleasing smiles. World J Orthod 2009;10:224-8.

12. Hasanreisoglu U, Berksun S, Aras K, Arslan I. An analysis of maxillary anterior teeth: facial and dental proportions. J Prosthet Dent. 2005;94:5308.

13. Umer F, Khan FR, Khan A. Golden proportion in visual dental smile in Pakistani population: A pilot study. Acta Stomatol Croat. 2010;44(3):168-75. http://www.ascro.hr/fileadmin/user_upload/2010/ number_2010-3/umer_10-3/umer_10-3.pdf. Accessed on October 15, 2010.

14. De Castro MV, Santos NC, Ricardo LH. Assessment of the 'golden proportion' in agreeable smiles. Quintessence Int 2006;37:597-604.

15. Murthy BVS, Ramani N. Evaluation of natural smile: Golden proportion, RED or golden percentage J Conserv Dent 2008;11:16-21.

16. Ward DH. A study of dentist's referred maxillary anterior tooth width proportions: comparing the recurring esthetic dental proportion to other mathematical and natural occurring proportions. J Esthet Restor Dent 2007;19:37.

17. Dong JK, Jin TH, Cho HW, Oh SC. The esthetics of the smile: a review of some recent studies. Int $\mathrm{J}$ Prosthodont 1999;12:9-19.

18. Wolfart S, Thormann H, Freitag S, Kerrn M. Assessment of dental appearance following changes in incisor proportions. Eur J Oral Sci 2005;113:159-65.

19. Basting RT, Trindade RS, Flório FM. Comparative study of smile analysis by subjective and computerized methods. Oper Dent 2006;31: 652-9. 